\title{
presión variable en ruedas neumáticas durante el movimiento
}

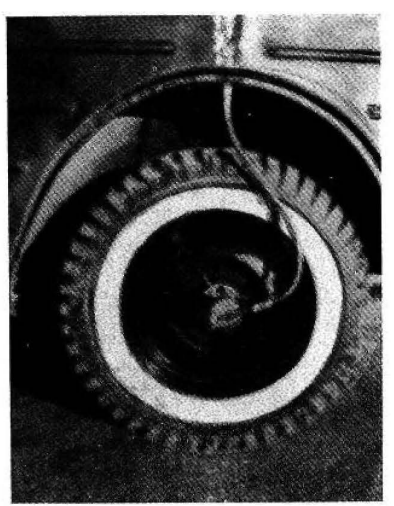

Las ruedas neumáticas pueden ser aciualmente infladas, deshinchadas y sometidas a cambios de presión, sin tener que detener el movimiento del vehículo.

Esto se logra mediante un equipo central de presión, puesto a punto por A. Schrader's (hijo), para los equipos de maquinaria de movimiento de tierra.

El sistema de "running inflation" permite ajustar la presión de las ruedas de acuerdo con el trabajo a efectuar, y características del suelo. Consigue un aumento de tracción en suelos blandos, arenosos, etc.

La parte esencial del sistema es la junta rotatoria, montada en el cubo de cada rueda. La parte giratoria de la junta está conectada a la válvula del neumático, siendo solidaria de la rueda, y estando la parte fija de la junta unida, por un manguito o latiguillo, al calderín de presión central.

M. CHINCHILLA 